\title{
Methods of eliminating waste from food packaging as a globalization tool
}

\author{
Daniela Salkova ${ }^{1}$, and Olga Regnerova ${ }^{1}$ \\ ${ }^{1}$ Czech University of Life Sciences, Department of Trade and Finance, Prague, Czech Republic
}

\begin{abstract}
The article deals with possible ways of elimination of waste from food packaging. It focuses on eliminating packaging waste through unpackaged food stores and the zero waste concept. Elimination of any waste in the form of packaging is an important element of protection and reducing the burden on the environment, and in this context also important element of globalization. The methodological approach is based on a field survey in the form of interviews with customers of a selected packaging-free shop and research aimed at identifying awareness and the use of packagingfree stores among the general public. The survey also included a comparison of prices of selected foods in the packaging shop and three hypermarkets. The aim of the article is to propose other possible ways to reduce packaging waste when buying food. The survey found that customers from 21 to 30 years old are most likely to shop in unpacked stores. The main reason for buying in unpacked shops is for most customers the effort to reduce the manmade environmental burden and the higher quality of the products sold. The most frequently mentioned disadvantage of this way of buying food is the limited range of products.
\end{abstract}

\section{Introduction}

The current society can be described as consumer both in terms of consumption of goods and in terms of consumption in general. Consumption far exceeds basic human needs. Excess consumption destroys the planet's resources due to the production of large amounts of waste. This requires high costs of energy, production or disposal of waste [1]. The environmental burden is associated with the accumulation of food waste with the subsequent formation of landfill gas, followed by waste of water and unnecessary soil destruction [2]. The elimination of waste produced is no longer just an economic issue, but the environmental impact is playing an increasing role in this endeavo [3]

Recently, it has been noted that, in addition to the legal requirements and regulations and directives of [4], the general public is generally more concerned about the environmental impact of waste [5]. A growing number of individuals feel responsible to address environmental risks in the global context [6]. Packaging waste is the most common waste. Examples include plastic bottles, microtene bags or various types of disposable packaging. Over time, the waste disintegrates into smaller parts - micro-plastics that seriously endanger the environment. The issue of packaging and waste materials has a major impact on sustainability. It is desirable to limit the production and consumption of packaging. It is essential that packaging management evolves towards higher environmental standards [7]. 
This can be achieved, inter alia, by adjusting the lifestyle to the so-called zero waste concept. With the help of packaging-free shops it is possible to reduce this waste to a minimum at the beginning. Waste prevention must be avoided, since the resources through which waste is removed or recovered are not endless. Management of packaging waste in the sense of reaching progressively better levels. However, there is still room for further improvement, particularly in the case of food waste management [8]. Waste prevention is possible with the help of packaging-free shops and zero waste households, which seek to protect the environment and eliminate waste.

A non-packaging shop is a shop where customers buy food into their own reusable packaging or containers, or they have the option to purchase back-up containers. These stores reduce packaging waste at the level of purchasing goods from suppliers. However, promoting alternative ways of sustainable shopping presupposes some customer education and overcoming barriers [9]. At the same time, it appears that ecological shopping is knowledgeintensive for consumers [10]. The subject that has a major influence on the purchasing behavior of customers in terms of green products is retail [11].

The Zero waste concept aims to prevent the generation of waste, ie not to generate waste at all. The concept disagrees with the transfer of waste to landfills or incinerators (about $20 \%$ of solid municipal waste is burned in Europe [12], since these waste disposal methods pollute the environment [13]. The amount of waste deposited needs to be reduced use [14]. Full utilization of material is critical to success or failure to achieve zero waste targets [15]. But this does not only mean the need to recycle, but above all the prevention of waste [16]. One of the goals is to encourage individuals to pursue sustainable natural cycles in their lives. It is also necessary to act on companies and manufacturers who must focus on the production of their products [17]. Waste prevention is also possible in households. According to [18], it is necessary to take individual steps to eliminate household waste so that the household becomes zero waste and does not generate excess waste. Zero waste reduces pollution and promotes protection of remaining natural resource [19].

The aim of the article is to map the awareness and use of packaging in the general public and to suggest possible ways of reducing packaging waste when purchasing food.

\section{Methods}

To map the use of packaging, their availability, raise awareness and identify the disadvantages of packaging from the point of view of current customers it was used field survey among customers of the selected selected packaging "Unpackaged". The survey conducted semi-structured interviews. Pre-prepared open questions, which were not ranked, were asked during the interview. Each customer provided a comprehensive answer. Customers were contacted directly at the point of sale. In total, 52 customers were contacted between September and November 2018. With the consent of the addressees, responses were recorded due to different length and content. The obtained data from interviews were processed by Microsoft Excel into tables and graphs and subsequently explained and described.

Interviewing of random respondents was done directly in order to find out the awareness and extent and way of using the packaging shops in the general public. The survey was conducted between October and December 2018. A total of 200 respondents were addressed. In terms of gender, a total of 105 women and 95 men were interviewed. In percentage terms, the ratio is $53 \%$ women and $47 \%$ men. The answers of the respondents, which were subsequently processed by Microsoft Excel into tables and graphs, were recorded using preprepared question sheets. The difference in food prices in non-packaging and packaging type of trade was investigated. The food prices of Nebaleno in its assortment were compared with three selected retail chains - Globus, Albert and Tesco. Prices are valid as of January 12, 
2019. Thirteen basic food categories (rice, pulses, seeds, nuts, cereals, flakes, flour, oils, dried fruits, sweeteners, salt, tea and spices) were selected from the Nebaleno shop assortment. One conventional type of food was randomly selected from each category (eg jasmine rice was selected from the rice category). These foods have been picked up because they are available in all grocery stores and they are among the commonly used foods. Due to the large supply in hypermarkets, it was necessary to take into account the average price of food calculated without discounts. The prices were recorded in a pre-prepared recording sheet and then compared. In the hypermarket, one random product was selected from each species to weigh the packaging. The emptied packages were weighed using a food scale and then converted into grams.

\section{Results and discussion}

The solved problems were mapped from the point of view of behavior and characteristics of customers shopping in a packaging shop, from the point of view of consumer packaging perception by the general public. At the same time, a price comparison of selected products of the packaging and retail chains was performed.

\subsection{How customers make purchases in non-packaging stores}

Based on the findings of the survey conducted among customers of the non-packaging store Nebaleno, it is possible to say that the customers from 21 to 30 years of age come to shop most. These data also correspond to the description given by the employees who stated during the interview that the most frequent customers are young mothers with children. This age category deals most with the issue and is aware of the current situation with packaging waste. In terms of percentage, it is a ratio of $83.3 \%$ women and $16.7 \%$ men.

The main reason for purchasing in non-packaging stores is for most customers the elimination of waste and, at the same time, the reduction of the human burden on the environment. Often these are customers who deal with the issue and they do not buy packaged products due to the release of substances from the packaging into the food. A more personalized approach to business, philosophy and business mission contribute to the popularity of these stores. Another reason often mentioned is the quality of the raw materials sold. Last but not least, the reasons for non-packaging purchase include a reduction in the need for garbage collection and the associated non-accumulation of items and the use of reusable packaging instead of disposable packaging. In view of the disadvantages that may discourage potential customers from purchasing in non-packaging stores, it has been found that the most frequently mentioned disadvantage is the limited range of products. The disadvantage of limited assortment was mentioned in half of the cases. Packaging-less shops offer rather "dry" and durable foods (rice, pasta, pulses, dried fruit, etc.). As the trade develops and grows, the range of products on offer is being expanded, but there are raw materials that cannot be obtained in packaging without packaging (yeast was often mentioned). The unavailable assortment concerns rather "wet" raw materials or raw materials that have a shorter shelf life (yeast, puree, sauces, pickled fruit and vegetables, etc.).

This is a big disadvantage compared to buying in a hypermarket, as most people are discouraged by the lack of product range. Shopping is often a matter of time. The customer wants to spend the shortest possible time in the shop and goes to a place where the required goods are accumulated as much as possible. The second most frequently mentioned disadvantage was the unavailability and small number of shops in the Czech Republic. According to customer feedback, availability should be increased to make shopping easier for potential customers. This opinion was recorded in $30.8 \%$ of responses, ie 16 customers. Another reported disadvantage of the packaging-less shopping method was the greater time 
consuming of the purchase. This way of shopping takes more time to "prepare". It is necessary to think in advance what raw materials will be purchased and in what quantity. By separating suitable food containers, which are often glass, buying becomes more difficult. The reason is also the weight and quantity of delivered packages.

The survey also investigated how customers learned about packaging-less shopping. It has been found that the most common way is to make recommendations through personal contact. Most (26 customers) are the people who have been recommended for this type of shop or who have been acquainted with the topic through personal contact. The Internet is the second most frequently mentioned source. 18 customers found out about packaging-free internet access. It was someone who had been interested in the issue of waste elimination before, so he intentionally sought this information over the Internet. Furthermore, it was someone who did not deal with the issue and accidentally came across an Internet article. More rarely there are the ways of finding through a newspaper article or accidentally discovering a shop during normal events and then attracting attention.

All interviewed customers who buy without packaging also go to the normal (packaging) type of shop. This was demonstrated in $100 \%$ of cases. Whether it is a large or small purchase rate, it is always a food that cannot be obtained without packaging, so it is necessary to buy it in ordinary stores. This is due to the fact that a limited assortment of food is offered in the packaging shops. It has also been proven in $100 \%$ of cases that it wears its own packaging (canvas bags for fruit, vegetables or pastry, etc.) to buy food and tries to choose products that are not packaged in plastic. Above all, emphasis is placed on glass, paper or fabric packaging that is easily recyclable or reusable.

\subsection{Awareness of unpacked stores for the general public}

In general, respondents were asked if they even knew about packaging-less food shops. It turned out that out of a total of 200 respondents, 126 had heard of packaging-less shops and knew they existed, which is $63 \%$. By contrast, 74 respondents (37\% of respondents) have never heard of packaging-less shops. With regard to gender, the results showed that $70 \%$ of women know this type of business and $30 \%$ do not. In the case of men, the situation is as follows, of the total number of 95 men in non-packaging stores, $56 \%$ have heard (specifically 59 men surveyed), the remaining 44\%, ie 36, have never heard of this type of business. It can therefore be said that women are more aware of the packaging-less shops. The respondents who stated in the previous question that they knew the packaging shops were asked whether they would go to such shops. Of those who know about the existence of these stores, 113 respondents said they still do not go shopping. The remaining 13 shop here.

The results also show that women go to shopping more without packaging. Of the total number of men, only $5 \%$ replied that they buy without packaging. For women, this figure is slightly higher, ie $14 \%$ of the interviewed women who know and buy packaging-free shops here. Specifically, $80 \%$ of women and $20 \%$ of men are familiar with the packaging and go shopping. Respondents who stated that they know the packaging business but do not go shopping there (ie 113 respondents) were asked to give a reason. Most respondents complained about poor accessibility of shops, especially from small towns or villages, with the fact that no packaging shop is located near their permanent residence. Furthermore, it has been reported that non-packaging shops are more expensive than traditional shops, and so it is not worth buying in non-packaging shops. According to respondents, hygiene is another reason why they do not buy them here. They are afraid of how bulk food is stored and treated, so they are more confident in packaged products. Regarding raw materials, potential customers are discouraged by a limited choice. The inconvenience, necessity of wearing own packaging also plays a big role. 


\subsection{Comparison of food prices of Nebaleno store with selected hypermarkets}

The survey compared prices of selected food at the Nebaleno store with three selected retail chains - Globus, Tesco and Albert. According to the respondents, food in packaging is more expensive than in traditional shops and therefore they do not buy here. However, a higher price level was not found for the non-packaging shop by comparing prices. Table 1 shows that in the Nebaleno store, prices for most products are lower than in all three compared hypermarkets. The lower price is marked in red in the table.

Table 1. Comparison of prices of selected products in case of no packaging purchase and purchase in retail chain $(\mathrm{CZK} / \mathrm{kg})$

\begin{tabular}{|l|l|c|c|c|c|}
\hline Category & Product & Nebaleno & Globus & Tesco & Albert \\
\hline rice & jasmine rice & 48 & 77,4 & 70,5 & 96,5 \\
\hline legumes & cheack peas & 65 & 73,8 & 66,8 & 59 \\
\hline seeds & chia & 179 & 161,8 & 189,6 & 183,4 \\
\hline nuts & walnuts & 349 & 500,8 & 366,1 & 519,4 \\
\hline cereals & bulgur & 63 & 52,8 & 51,8 & 63,8 \\
\hline flakes & oat meal & 33 & 42,8 & 48,5 & 42,8 \\
\hline flour & bread weat & 21 & 22,9 & 23,4 & 31,7 \\
\hline oils & rapeseed oil & 44 & 49,9 & 44,9 & 47,9 \\
\hline dried fruits & dried apples & 259 & 321,4 & 379,3 & 398,7 \\
\hline sweeteners & sugar groats & 21 & 68,9 & 53,7 & 40,8 \\
\hline salt & iodine salt & 17 & 24,8 & 24,3 & 28,5 \\
\hline tea & green tea & 599 & 1068,4 & 877,5 & 1023,9 \\
\hline spices & basil & 790 & 1586,4 & 1390,8 & 1797,3 \\
\hline
\end{tabular}

For rapeseed oil, all four stores are identical products from the same supplier. The full product name is Fabio Manka Rapeseed Oil. Therefore, it can be concluded that the price of oil in Nebaleno is lower because it is sold without packaging. The price difference between the packaging and the packaging product should therefore be the price that the buyer pays only for the packaging. The biggest price difference can be seen for green tea and basil products (the price difference is up to double). This is because these products are sold in small packs and small quantities in hypermarkets. For example, basil is sold in hypermarkets in packs of 9 to 12 grams, for an average price of CZK 16 per 10 grams, which is equivalent to a final price of CZK 1600 per kilogram. When purchasing products in packaging, it was also monitored how much more waste the customer would produce when shopping in a hypermarket instead of an unpackaged shop. For this purpose, one random sample of the product was selected.

The values are shown in Table 2 with respect to the weight, type of packaging and number of packages. In terms of the type of packaging, it was most often a plastic packaging material. However, this does not mean that it is the only packaging material in which the product is sold. The individual packages were then weighed.

It has been found that when purchasing the 13 products in packaging, this generates 132 grams of waste more than in an unpackaged shop. 34 pieces of disposable packaging would be created in the pieces, which after use of the product inside can no longer be used and the packaging is thus thrown away. The number of pieces in the green tea package consists of 21 packages, as each individual bag with loose tea is packed separately.

Based on the investigations carried out and the findings, it is strongly recommended to raise awareness of the packaging-free way of shopping. The findings of the field survey showed that $37 \%$ of the 200 respondents surveyed had no information about non-packaging stores. Given that $34 \%$ of the shoppers surveyed learned without a package purchase via the Internet, 
it is therefore important to expand the promotion in this form. Because it is a zero waste business that does not want to produce unnecessary waste of any form including promotion and advertising in paper form. It is therefore recommended to increase promotion without packaging stores in electronic form.

Table 2. Information on packing

\begin{tabular}{|l|l|c|c|}
\hline Produkt & Type of packing & Number [pcs] & Packing weight [g] \\
\hline Jasmine rice & Plastic & 1 & 6 \\
\hline Cheack peas & Plastic & 1 & 5 \\
\hline Chia & Plastic & 1 & 4 \\
\hline Walnuts & Plastic & 1 & 6 \\
\hline Bulgur & Plastic & 1 & 6 \\
\hline Oat meal & Plastic & 1 & 4 \\
\hline Bread weat & Paper & 1 & 40 \\
\hline Rapeseed oil & Plastic & 1 & 14 \\
\hline Dried apples & Plastic & 2 & 10 \\
\hline Cukr krupice & Paper & 1 & 10 \\
\hline Fine iodine salt & Paper & 1 & 14 \\
\hline Green tea & Paper & $1+20$ & 3 \\
\hline Basil & Plastic & 1 & 40 \\
\hline
\end{tabular}

The results also showed that the main reason why a potential customer who is already informed about the shop is not able to buy into the packaging shop is the poor availability and the small number of stores. It turned out that even for today's customers the big disadvantage is the unavailability of stores, but they are still willing to continue shopping and commuting (this disadvantage was mentioned in more than $30 \%$ of cases). The unavailability of the store will deter a large number of potential buyers. The packaging-free shops are concentrated mainly in the centers of larger towns and are less frequent in the peripheral parts. Classic retail chains are easily accessible in more populated areas and on the outskirts of cities. Using forms of promotion, the store would attract more customers and could afford to expand the chain across multiple locations.

Another possible solution is to extend the food distribution service. Another major disadvantage for both current and potential customers is the limited supply of raw materials sold. The assortment consists largely of "dry" raw materials (pasta, seeds, pulses, etc.). Therefore, it is recommended and necessary to supplement foods that are "liquid", ie those that have a shelf life (pickled foods, sauces, purees, etc.). Due to the limited assortment, customers are forced to buy food that is not available in non-packaged form packaged in other stores. Packaging-free shopping has a clear benefit in the elimination of packaging waste. Thanks to this, packaging waste can be kept to a minimum while minimizing the human environmental burden. When purchasing basic groceries in an ordinary shop, which was made mainly to compare prices between selected stores, there were produced 34 pieces of disposable packaging. After weighing the packaging itself, it has been found that the total weight is 132 grams, which in the long run may amount to several tens of kilograms of packaging waste. It should be noted that this is the weight and quantity of packaging from only 13 products.

The general public should be aware of these impacts and seek to reduce their overall consumption. In spite of the commercial pressures, many grassroots initiatives have developer hybrid oraganisational forms that are organised around a social mission. [20] Advantages of without packaging stores include the fact that you can buy the exact amount of food you require in an unpackaged shop, so there is no food waste. The price in nonpackaging stores is determined by the weight of the food purchased. In conventional stores, prepacked food is sold in pre-set quantities, which are often unnecessary. An important result 
of the investigation was the finding that customers are mistakenly concerned about higher prices in non-packaging stores. This assumption was rebutted by comparing prices. On the contrary, it turned out that $77 \%$ of food is cheaper in the non-packaged store Unpacked compared to the average prices of food offered in selected retail chains. It is possible to buy food without unnecessary packaging, the higher the price can be caused by simply wrapping food.

\section{Conclusion}

Over the past 200 years, mankind's activities have changed the planet's operations to such an extent that it is possible to speak of the destructive use of natural resources. It is now clear that mankind is on the verge of far-reaching change. These changes will not be easy and pleasant for society at all. Climate change, air pollution, fresh water loss, melting icebergs, underground fresh water reservoirs are decreasing, and the environment is also enormously polluted by producing large amounts of waste. Society should not be indifferent to these issues and should be aware of the environmental impact of its activities.

The issue of packaging waste may look numb compared to the above problems. Eliminating the amount of food packaging may seem to be seen as a small part of reducing the planet's environmental burden. But it is necessary to view this issue as a whole and further efforts to improve. Neither, these seemingly small topics can be neglected, and any suitable initiative must be accepted as a necessary plus in the field of eliminating food packaging and its contribution to the environmental burden.

As a result, informing citizens who can participate and contribute to reducing disposable packaging and reducing the use of food packaging can have a significant impact on environmental protection. The company should put pressure on the legislator to introduce standard returnable packaging, as well as pressure on the food chains to adopt and support this idea. Customers in unpacked stores can thus help with their approach to promoting ideas at national and international level.

\section{References}

1. T. Ekvall, G. Assefa, A. Bjorklund, O. Eriksson, G. Finnveden, What life-cycle assessment does and does not do in assessments of waste management. Waste Management 27, 1422-1429 (2007)

2. P. Varvazovska, M. Prasilova, Waste Production as One of The Problems of Postmodern Society, 2nd Global Conference On Business, Economics. Management And Tourism. Procedia Economics and Finance 23, 1674-1679 (2015)

3. J. C. Powell, The evaluation of waste management options. Waste Management \& Research 14, (1996)

4. M. D. Bovea, J. C. Powell, Alternative scenarios to meet the demands of sustainable waste management. Journal Of Environmental Management 79, 115-132 (2006)

5. A. Emery, A. Davies, A. Griffiths, K. Williams, Environmental and economic modelling: A case study of municipal solid waste management scenarios in Wales. Resources Conservation and Recycling 49, 244-263 (2007)

6. J. Connolly, A. Prothero, Green Consumption Life-politics, risk and contradictions. Journal Of Consumer Culture 8, 117-145 (2008)

7. A. Lombrano, Cost efficiency in the management of solid urban waste. Resources Conservation and Recycling 53, 601-611 (2009) 
8. L. Rigamonti, A. Falbo, M. Grosso, Improving integrated waste management at the regional level: The case of Lombardia. Waste Management \& Research 31, 946-953 (2013)

9. Ch., Fuentes, P. Enarsson, L. Kristoffersson, Unpacking package free shopping: Alternative retailing and the reinvention of the practice of shopping. Journal Of Retailing And Consumer Services 50, 258-265 (2019)

10. Ch. Fuentes, Managing green complexities: consumers' strategies and techniques for greener shopping. International Journal Of Consumer Studies 38, 485-492 (2014)

11. H.,Guyader, M., Ottosson, L. Witell, You can't buy what you can't see: Retailer practices to increase the green premium. Journal Of Retailing And Consumer Services 34, 319325 (2017)

12. R. Turconi, S. Butera, A. Boldrin, M. Grosso, L. Rigamonti, T. Astrup, Life cycle assessment of waste incineration in Denmark and Italy using two LCA models. Waste Management \& Research 29, 78-90 (2011)

13. G. Romano, A. Rapposelli, L. Marrucci, Improving waste production and recycling through zero-waste strategy and privatization: An empirical investigation. Resources Conservation and Recycling 146, 256-263 (2019)

14. A. Emery, A. Davies, A. Griffiths, K. Williams, An in depth study of the effects of socioeconomic conditions on household waste recycling practices. Waste Management \& Research 21, 180-190 (2003)

15. D. K. Sharma, S. Bapat, W. F. Brandes, E. Rice, M. J. Castaldi, Technical Feasibility of Zero Waste for Paper and Plastic Wastes. Waste And Biomass Valorization 10, 1355 1363 (2019)

16. Zero waste Europe. What is Zero Waste [online]. [cit. 2019-01-03]. Available at: www: https://zerowasteeurope.eu/what-is-zero-waste/. (2019)

17. R. Murray, Zero Waste. (Greenpeace Environmental Trust, London, 2002)

18. B. Johnson, Domacnost bez odpadu: jak si zasadne zjednodusit zivot snizenim produkce odpadu. (PeopleComm, Prague, 2016)

19. R. Strapasson, S. C. Amico, M. F. R Pereira, T. H. D. Syclenstricker, Tensile and impact behavior of polypropylene/low density polyethylene blends. Polymer Testing 24, 468473 (2005)

20. L. Lambert, T. Dedeurwaerdere, M. Nyssens, E. Severi, O. Brolis, Unpacking the organisational diversity within the collaborative economy: The contribution of an analytical Framework from social enterprise theory. Ecological Economics 164 (2019) 